\title{
Aporetic Anagnorisis. Recognition of Freedom in Moravia's Novels of the 60s
}

William Slaymaker

The Empty Canvas (1961; La noia, 1960) and The Lie (1966; L'attenzione, 1965) are dramatic philosophical narrative investigations of alienation and decadence. As such, they are integral to Moravia's fictional oeuvre. While the themes and characters of these two novels are found in his earlier as well as later fiction, the types of narrative structures and philosophical analyses make the two novels of the 1960 s unique.

Until the publication of The Empty Canvas, Moravia had relied on Marxist and Freudian concepts of alienation and cultural decadence for his narrative investigations into the social and sexual conflicts of his characters. In addition to Marx and Freud, the two novels of the 1960s reveal the influence of Moravia's reading of Wittgenstein and phenomenologists such as Husserl, Heidegger and Jaspers. This reading, coupled with an existentialistic humanism developed in his postwar essay "Man as an End," made Moravia's narratives more obviously philosophical.

Moravia realized as he was writing The Empty Canvas that he was essentially dramatizing a dialectic of ideas in narrative form. This realization, together with his growing belief that the theatre was the best medium for an analysis of conflicting ideas, motivated him to write and stage three plays between 1966 and 1969: The World is What it is (Il mondo è quello che è), The God Kurt (Il dio Kurt), and Life is a Game (La vita è gioco). The titles of the first and the third plays reveal Moravia's adaptation of Wittgenstein's concept of the tautology developed in the Tractatus, and the description of reality by means of language games, proposed in The Philosophical Investigations. The second play, The God Kurt, is an adaptation of Sophocles. Moravia's dual concern in the 1960 s with drama and philosophy produced two novels which are conceptually complex and rhetorically rich.

Given this intellectual background, it is natural that Moravia's novels of the 1960s deal with the conflict of freedom (and its ancillary concepts: free will and choice) and nonfreedom (and its correlatives: fate, destiny, necessity and determinism). He dramatizes in these two novels the conflicts of male artist/intellectuals who believe they are free, act as if they can intend and will actions that demonstrate autonomy, but come to recognize that they are also not free to be and do what they will. The dramatic recognitions or 
anagnorises which occur in the novels are presented in logical and rhetorical modes that may be described as aporetic.

The narrative modes of The Empty Canvas ${ }^{2}$ and The $\mathrm{Lie}^{3}$ are aporetic in several different senses of the Greek term aporia. The novels are aporetic narratives in a logical and philosophical sense. In the Metaphysics, Aristotle inspected and attempted to resolve some of the logical problems and puzzles (aporiai) of Zeno of Elea. While Moravia's narrative aporetic of freedom and nonfreedom resembles Aristotle's dialectic of resolution, it is closer to the aporetic phenomenological description that the German philosopher Nicolai Hartmann (1882-1950) gives of the antinomies of human free will and determinism. Hartmann argues in Moral Freedom, the third volume of the translation of his Ethik (1926), that metaphysical problems such as that of free will and determinism are insoluble. He attempts to find a way through what he labels the aporiae or dilemmas of human freedom by unraveling the strands of this logical conundrum, inspecting the contradictory positions, and finally resolving the contradictions partially by positing a middle way. Though there is no evidence that Moravia read or borrowed from Hartmann, nonetheless his narrative strategy is similar. His protagonists recognize their dilemmas of freedom and nonfreedom, and they seek a way out or a way through the horns of dilemma. The Greek terms aporia and aporos mean, in addition to the definitions given above (problem, puzzle or paradox), difficulty of passage and paths or ways beset by barriers and impediments. Moravia's protagonists search desperately for a way or ways out of their dilemmas, but find no convenient existential exits. Suicide surfaces as a way out, a choice and an action which assert freedom, but their feeble attempts at decisive action are always unsuccessful.

The protagonists in The Empty Canvas and The Lie seek to resolve the aporiae or paradoxes of life by investigating those human beings who can accept life as it is lived or who neither question nor examine their reality and thus seem to have found a way out or through the dilemmas of existence. Moravia's artist/intellectuals seek clues to unalienated existence in the tautologous lives of others who simply are what they are. It is here that Moravia is indebted to the Tractatus for its concern with the logical concept of tautology and its relation to reality and human freedom. Moravia has repeated on numerous occasions his indebtedness to the Tractatus as an inspiration for his narrative development of the concept of tautology, though his adaptation is neither rigorous nor easy to construe. In the Tractatus, statements that make sense and say something about our reality are those which fall logically between tautologies and contradictions. The latter are not nonsensical but they also are not pictures of reality (4.462). A tautology is a logical proposition that leaves open the whole of logical space just as a contradiction closes off logical space. As such, a tautology cannot "determine a reality in any way" (4.463) because necessity operates only in a logical world and "outside logic everything is accidental" (6.3). Freedom of the will is simply a projection 
of intentions in a real not logical world where accident, not exact causal knowledge, is the case (5.1361).

Moravia constructs characters, usually women, who are not logical but living tautologies. He describes them with self-identity formulas such as "she is what she is." His feminine characters exist as tautologies in reality, not as pure logical propositions as Wittgenstein would have them. As tautologies, these characters either accept their reality or attempt no analyses of their conditions. The language given to them is the language that adequately describes their reality. They question neither worid nor word, or if they do, they eventually accept the synonymity of word and object. And true to the final proposition of the Tractatus, what cannot be spoken of, is left in silence.

Moravia's artist/intellectuals, on the other hand, resist the linguistic limits of their world. They discover they themselves are contradictions, actually and logically. In relation to freedom and nonfreedom, they find themselves caught between logical concepts where truth is necessary and determinable, and a real world where intended acts, which appear logically true, go awry. They learn that any correlation between what is logically intended or expressed and what actually happens is accidental. This kind of Wittgensteinian uncertainty about casual relations disturbs them. They see themselves as nonfree because, unlike their tautologous counterparts, they cannot simply accept what is and become a part of the flow of things outside the necessity which obtains in logic. Moravia's protagonists are contradictions in the sense that they are free and not free. They are free to accept the world as it is and live in it, yet their analytical minds and their rejection of a simple unexamined existence (their alienation) make this choice impossible. They inhabit an ideal logical space and a real world where the tautologous existence of their feminine counterparts beckons. The aporial escape or way through this dilemma would be that transcendental ladder which, by means of contemplation, leads out and beyond the real world. Perhaps Moravia had in mind Wittgenstein's famous ladder metaphor (6.54). The protagonists struggle to transcend and escape the polarities of their freedom and nonfreedom. In vain they attempt to climb out of an alienated solipsism and transcend the limits of language. They recognize they are inextricably caught in the net of existence. They see that there is no excluded middle, no third way between the aporiae of freedom and nonfreedom.

The original title of The Lie, L'attenzione, points to the importance of Moravia's reading of phenomenology. In this novel the protagonist examines or attends to the lives around him. He tries to comprehend how it is that they can accept the reality of their situations. The mysterious combinations of freedom and nonfreedom cause not great consternations or irruptions in their existence. The protagonist recognizes his inability to make a transcendent dialectical synthesis out of the thesis (freedom) and antithesis (nonfreedom) of his life or the lives of others. He can only attend to the dilemma and give an accurate description of the phenomena as he perceives them. $\mathrm{He}$ 
writes a diary which becomes a novel. The novel/diary is a projected way out of the insoluble paradox of human life. While the artist/protagonist sees his freedom in the recreation of what he has observed and thought, he also recognizes that he is trapped in the necessarily alienating aesthetic enterprise of attempting to capture in words what cannot be truly captured. He is caught between the truth of reality, which is lived, and the lie of artifice, which is verbalized. Further, he recognizes he cannot control his attempts to capture reality, leading invariably to imaginative prevarications of truth. The play and display of words are not ways out.

In addition to the philosophical or logical sense, Moravia's narratives are aporetic in the contemporary deconstructionists' sense of aporia as well as in the traditional classical rhetorical sense. Paul de Man in Allegories of Reading writes that "Rhetoric radically suspends logic and opens up vertiginous possibilities of referential aberration" (10). From a reading of Nietzsche, de Man derives a meaning of aporia as a "gap" that "allows for two incompatible, mutually self-destructive points of view" (131). Moravia's protagonists in The Empty Canvas and The Lie discover they cannot read their own cultural or personal contexts. They are confused by the interference between how they interpret reality and what reality is. The possibilities of interpretations of the actions and motivations of others are vertiginous. In addition, we, the readers, are asked to interpret, not accept, the protagonists' interpretations. Especially in The Lie, a Gidean novel/diary resembling The Counterfeiters, we encounter the aesthetic postures of the protagonist's manifold doubts and dilemmas in regard to truth, reality and human freedom. Here, rhetoric turns back on logic and suspends its attempts, like Aristotle's dialectic or Hartmann's antinomic phenomenological analysis, to lay out the path between the aporiae. Moravia, as an artist and not a philosopher, does not reduce his analysis to antinomies for the sake of resolution, but magnifies and multiplies entities until his narrative art becomes a labyrinth of possible interpretations.

In the classical sense of aporia, the protagonist's confessional narratives are expressions of doubt, related to the figure dubitatio, which appeal to the audience to appreciate and participate in their conundrums. Traditionally, aporia carries the sense of the rhetorical question: How shall I proceed? How can the question be answered? As such, the novels are open-ended appeals for answers to the protagonists' recognitions that freedom and nonfreedom operate to frustrate their actions and intentions. The novels end in positions of skeptical doubt, without resolution, with appeals to us to understand that they are no longer certain how to proceed and must abandon their previous investigations into the logical problems which have alienated them from life. The brief conclusions to both novels, titled "Epilogue" (the Greek rhetorical equivalent of peroratio), are recognitions that try not to convince or persuade us, but raise doubts about solutions to the instability of the human condition. The knowledge gaps opened between the protagonists and reality, and between protagonists and readers, are not closed but disclosed. The freedom 
and nonfreedom of human existence are constantly in the state of discovery as Moravia emphasized in his essay "Man as an End."

If we follow de Man's analysis of the rhetorical question in the opening chapter, "Semiology and Rhetoric," of Allegories of Reading, we come to recognize that Moravia does not help us to pursue or answer the narrators' question: How shall I go on? It is, in part, a conflict of grammar and rhetoric that makes a pertinent reply impossible; but even more, it is Moravia's intent to leave the answer to the question in the realm of possibility and discovery. This discovery applies to Moravia, the narrators/protagonists of his novels, and to us. Given this state of affairs, it is indeed difficult to establish whether there is blindness and insight in both a de Manian and Sophoclean sense, or blindness without insight. Blindness is quite obviously a part of the reading of The Empty Canvas and The Lie. We share with the narrators of the novels their confusion, their misinterpretations and mistakes. We do not know how to go on or how to proceed with their investigations into the aporiae of freedom and nonfreedom. Like the narrators, we encounter the Sophoclean blindness of not knowing or understanding human destiny. As de Man sees it, this oedipal blindness is caused by the "absolute ambivalence of a language" (Blindness 185).

In spite of the pessimistic Stoicism which pervades the mood of the epilogues of The Empty Canvas and The Lie, we cannot help but recognize that the awakenings or conversion experiences in the conclusions offer insights into possible paths through and out of the dilemmas of human existence. In spite of the narrators' and readers' confusion, Moravia offers the tentative insight of discovery as the answer to the question: How shall I proceed? By the end of the novels, freedom has become the rite (right?) of discovery that it is suffering that causes us to read the expressions of our humanity with intense interest and despair. Caught we are, but read we must in order to see into and perhaps masochistically enjoy our inability to control willfully our human behavior which includes language.

A reading of The Empty Canvas reveals that the aporiae of freedom and nonfreedom are entailed in the protagonist Dino's boredom. Dino cannot establish any meaningful relationship with reality. As he confesses in the "Prologue," he is unable to represent to himself or attend to objects external to his consciousness. Some external objects remain real, but others lose their special relationship to his consciousness and become absurd. The root of his suffering is the recognition that, while objects do exist and he should be able to will a relationship with them, he is unable to do so consistently. Dino is plagued by his inability to live and think as he believes he ought in a world full of being.

Moravia uses the phrase "the withering of objects" (4) ["l'avvizzimento degli oggetti," 9] in the "Prologue" and throughout the novel to describe the essential problem Dino endeavors to resolve during the course of his narrative. Dino has turned to painting in an effort to establish contact with things by 
recording them on canvas. The political and social worlds he inhabits have dried up long ago. He is bored and suffocated by ideologies, sex, wealth and family position. Above all, money captures him in an inescapable way which he calls "the feeling of compulsion, or predestination" (13) ["il senso di determinazione e di predestinazione," 19]. And while he believes he can restructure his ideas about his place in life, he doubts he can liberate himself from his feeling of predetermination because, as he argues, feelings cannot be rationally altered or displaced. Thus, Dino feels helpless to modify the data of his life. His wealth and social position are conditions he can do nothing about. It is a sense of bedevilment against which he has no notion how to proceed. He cannot escape his feelings because he cannot escape from self. At the same time, he has no particular or definable relationship with self $-a$ useless fragmented object with which he has become bored like the rest of reality.

Dino's painting does nothing to overcome the barriers which exist between feelings, conscious rational thought and external reality. Neither music nor colors on a canvas communicate with the sensibility of boredom and despair couched in self. He cannot establish a relationship with books because boredom blocks all participation in aesthetic experiences. Thus, even aesthetic action is added to the list of impotent acts. Actions themselves, of whatever sort, as well as willful intentions to act, make reality or even consciousness of reality no more acceptable or believable to Dino. He is a prisoner of a self which has feelings that cannot be willed, changed or altered. The suffering comes with the belief that he should and ought to be able to escape. Death is not a desirable alternative, but neither is his life. Between these choices the dialectic, the aporetic logic, of the body of the novel oscillates. Having analyzed in essay form the problem of boredom, the narrator moves on to the dialogues between himself and his mistress Cecilia. The brief essayistic "Prologue" which laid out the dilemma of freedom and nonfreedom sets the stage for the lengthy dramatization of this particular paradox as well as related philosophical problems.

The dramatic action in the main body of the novel is a result of Dino's analyses of his actions and motives, and his confrontations with his mistress Cecilia and his mother. Moravia's narrative oscillates between Dino's confessional introspections about the nature of his boredom and his acting out of those thoughts which result from his meditations. While Moravia's analyses of Dino's boredom are essentially essayistic narratives which focus on a thesis, investigate causes, argue from assumptions and draw conclusions, the dialogue between Cecilia, Dino and his mother are tense dramatic confrontations which take various dialogic forms from mild conversations to Socratic elenchi. But more often, they are inquisitorial and interrogatory cross-examinations. In general, the nine body chapters are introduced and concluded with the essays which function as mini-prologues and epilogues to each chapter. The dialectical clashes between characters flesh out the essay 
narratives by giving substance and human voice to the abstract ideas which dominate Dino's conscious life.

The first chapter of the novel's main section concentrates on Dino's relationship to his mother. This relationship, like his relationship to all things, is tenuous and fragile. In order to learn why he is restless and unable to relate to the reality surrounding him, he questions his mother closely about his errant father. He recognizes that while he is restless like his father, he does not resemble him in other ways. There are no explanations for his philosophical and emotional quandaries to be found in the pursuit of genealogy. Certainly he has not inherited his mother's penchant for acquiring wealth and social status. She believes in money and her relation to reality is conditioned by that belief. Her religious pieties are connected to her desire for social respectability and middle class solidity. She attends church with the same punctiliousness she devotes to business affairs. Moravia reveals the money orientation of Dino's mother through the cross-examinations and conversations Dino conducts to determine whether or not he should resume his old lifestyle at home. A return to his former life means, as Dino clearly recognizes, a return to impotence and boredom, and what he labels the "mechanism of despair" (51) ["meccanismo . . . della disperazione," 61]. There is a machinery of relationships to people and things that Dino discovers is absurd and inescapable. This recognition brings about his flight back to his studio. There, the empty canvas awaits him as a reminder of his aesthetic inactivity and instability. His refusal to live at home and resume his former life is an act of rebellion and superficial freedom.

After a brief disquisition on the madness of the painter Balestrieri who believes in the illusion of reality, Dino encounters and interrogates Cecilia, the teenage femme fatale who has led Balestrieri to an untimely death and promises to do the same to Dino. Dino contemplates the "destiny" (87) ["destino," 101] that linked her to Balestrieri. And he recognizes, as a result of his cross-examination of Cecilia and his meditation on Balestrieri's fate, that he shares the painter's destiny. Yet, there is a difference-consciousness. The traditional Moravian concern with knowledge surfaces here in the novel. By the end of the second chapter, Dino thinks it may not be possible to escape fate; nonetheless, there is a qualitative difference between the conscious and unconscious acceptance of destiny. Dino believes that Balestrieri died because he did not know or see Cecilia as the fatal instrument of his death. Dino, on the contrary, believes he sees and knows. He no longer rejects $\mathrm{Ce}$ cilia's sexual advances, but willfully accepts her and pursues the relationship. As he admits later in Chapter seven:

It was as though, having recognized the vanity of my efforts to stop myself on the slope down which Balestrieri had plunged, I had now decided to deliberately do the things he had done before me, as if doing them consciously and of my own free will ["di mia volontà e consapevolmente," 233] had now become my only means of distinguishing myself from him, since he had done these things in spite of himself 
and in a state of unconsciousness bordering on madness. (206) [emphasis mine]

Dino's willfulness and deliberateness is, however, tentative and hypothetical. Curiously enough, his hand signal to Cecilia not to leave him is an imperceptible and unintended action, yet loaded with consequences. In a casual almost unconscious way the fated relationship with Cecilia begins. Subsequent to Chapter two, the narrative proceeds to investigate this destined relationship through Dino's revealed observations about her mystical impenetrability as a real but unobtainable object and through the intense cross-examinations to which he subjects her as he begins to suspect her infidelity.

Dino's love affair is solipsistic. He can know Cecilia sexually, but not otherwise. His relationship to her is like his relationship to reality, yet he is not bored. He is fascinated and trapped by her existence as a thing apart. She cannot be captured, verbally or physically. Automatic and mechanical in her lovemaking, Cecilia does not suffer like Dino from the lack of contact with things, a state which causes boredom and suffering in Dino but is normal and acceptable to her. His illness is her health. She feeds on him. Or so it seems to Dino who can only interrogate her about her thoughts and feelings but never penetrate them or understand them. Moravia, by the middle of the novel, has totally immersed Dino in the dialectic of dramatic incomprehension. While Cecilia is simply sustained by the sexual relationship which is natural and necessary to her, the intellectual Dino feeds on new questions and uncertainties. He oscillates between a growing boredom with the sexual act which seems unnatural and unnecessary, and a continued fascination with Cecilia's opacity. At this point, Moravia, as a narrative strategy, alternates dialogue and Dino's introspective revelations. Moravia provides simple narrative transitions such as "This is an example of one of those conversations," or "Here is an example of how I questioned her" between dialogues and speculative meditations. Both lead inevitably into blind alleys, never into resolutions of aporiae, for us and for Dino.

Dino's interest in Cecilia and our interest in Dino at the midpoint of the novel would most certainly dry up if Moravia had not introduced Cecilia's love affair with Luciani. The uninterrupted parade of despairing formulas, puzzles about reality and truth, and repetitious introductions of lifeless interrogations taxes our patience. However, as soon as Dino knows that Cecilia is dissembling in her naive but natural way, as soon as he discovers that she is an object of value to another, then Dino's (and our own) interest in the narrative picks up speed.

Liberation from boredom is what Dino seeks at the beginning of the novel. As the conclusion to the body of the novel approaches, he seeks the liberation of (not from) boredom because he finds himself trapped in his desire for Cecilia, a physical as well as intellectual desire to penetrate and possess her completely. But even a liberating boredom is unobtainable: 
Possibly I was seeking, in her unalterable docility, a reason for boredom ["noia"] and thus for liberation ["liberazione"]. But Cecilia's body was not Cecilia, and what Cecilia was, I did not succeed in finding out. As for her docility, it no longer produced any boredom in me, but rather a profound mistrust, like I could not contrive to escape ["non riuscivo più a liberarmi," 229]. (202)

Dino is trapped. He cannot nullify her independence or mystery for money or for love. He cannot completely possess her, trap her, objectify her even in death. If he murdered her, she, not he, would be liberated by death. Dino's life is a series of logical contradictions: he is the possessor and the possessed, the judge and the condemned, and the bored and the fascinated. Because he can discover no way out of his destined dilemma, he decides to kill himself.

At the outset of the body of the novel, Dino had unconsciously signaled Cecilia to come to his studio room. Dino's suicide attempt is similar. Unconsciously, almost unintentionally, he drives off the road while passing a truck, striking a plane tree. Dino explains his action as a mystical turning, "as though I had really seen another road on my left into which I wanted to turn" $(302 ; 341)$. This "seeing" is the major anagnorisis in the novel. It is the way, the hole that beckons. It does not exist in reality; it is the logically excluded middle; nonetheless, it exists for him as an aporia in the sense of a path out of the paradoxes of his existence. For Dino, this road leads to final liberation - death.

Moravia never grants his protagonists the grace of a successful death. Recovering in his hospital room in the "Epilogue" of The Empty Canvas, Dino contemplates a Cedar of Lebanon outside his window. He recognizes, finally, that objects which exist independently and have no relationship to him must be accepted without possessive desire. This recognition is extended to Cecilia. He believes he can now accept her as an autonomous existence without need to possess her. He learns, through contemplation and meditation, to will the existence of other things. Things begin to exist when they are not possessed. This relinquishment means a new kind of love for Cecilia. The old love died in the accident.

As is typical for Moravia's more recent novels, there is no resolution at the end of The Empty Canvas of the complex paradoxical relationships Dino had formed with Cecilia. In the very last paragraph of the novel, Moravia leaves Dino with his aporetic gesture of rhetorical "doubt" (306) ["il dubbio," 347]. Dino does not know whether his relationship with reality will really change. He is not certain that his new love for Cecilia and things will replace his boredom. He is unsure that he will be able to paint again and fill in the empty canvas waiting in his studio. Only living will bring the discovery of genuineness.

With the final appeal to doubt about the meaning of past and future experiences, Moravia challenges us to the frustrating task of rereading and unraveling the confused threads of narrative argument. Dino recognized near 
the end of the body of the novel that "contradiction is the fickle and unforeseeable basis of the human spirit" (261). While he seems ready to accept the aporiae or antinomies of the logic of life, are we prepared to accept the confusions and contradictions of his narrative? For example, in the "Prologue" we learned that things, such as a tumbler, are real and not boring or absurd for Dino to the extent of their closeness to him. Boredom and absurdity reveal themselves when objects wither away or become distant or have no relationship to consciousness. If we attempt to apply this formula to Cecilia, we encounter difficulties. Dino feels that he has a certain relationship with Cecilia - basically a physical one. True to the above formula, Dino's sexual interest wanes when Cecilia's body becomes more distant; sex begins to appear absurd and the relationship becomes boring. At this point, Dino desires to dump Cecilia. However, as her infidelity and mendacity are revealed, she becomes more interesting and less boring not because he can keep her, like a tumbler, well placed in a certain relationship in his consciousness, but quite the contrary, because she becomes even more distant and less explainable as an object not to be possessed or understood. Thus we experience the double frustration of Dino's frustration and our own puzzlement. After all, we ask, is she boring and unreal or isn't she? Unlike the tumbler, the more elusive and distant she is, the more real she becomes as an object of his fascination. The more often he has her physically, the less he possesses her. The more she lies and removes herself from truth and reality, the more real she becomes as an object. And in this lying, puzzling creature Dino sees reality and is revolted by it as well as attracted and interested.

As readers, should we accept the incongruence of the narrator's analysis of boredom? While most of us, like Dino, have not succeeded in reducing life to logic, nonetheless, we still expect some grammatical and lexical precision in narrative. Though we are prepared as "modern" readers to be blinded by the protagonist's confusion, we hesitate to accept and acknowledge our own. Further, we are inclined to ask if the author himself is not confused. Translating this confusion to the problem of freedom and nonfreedom, we find that the analytical contradictoriness of this irresolvable paradox makes us suffer with the protagonist, but neither we nor Dino gains any definite wisdom beyond the recognition that reality is tautologous - it is what it is. At this point freedom and nonfreedom become a pseudo-problem unworthy of pursuit. The aporiae or gaps between Dino's reading of his situation, our efforts to sift through his statements, and what we believe Moravia intends us to understand Dino to mean, become vertiginously deep and wide. Rather than let critical speculation run riot, it is best (if not intellectually comforting) to take the final Stoic but skeptical anagnoretic insight or recognition Moravia's narrator offers - in the face of doubt, let life be and live - and move on to the next dramatic lesson in frustration, The Lie.

The Lie is structurally similar to The Empty Canvas. A lengthy confessional narrative is sandwiched between a prologue and epilogue. The body of 
this novel is the narrator Francesco's diary entries from which he intends to extract a novel. The "Prologue" explains why the diary was kept, introduces major characters and lays out the major problems to be analyzed. The main problems under scrutiny are these: Francesco feels shame for his loss of love for his wife Cora, and he hopes by paying close attention (the Italian title of the novel) to the causes of his disinterest to discover what is wrong with himself. He decides to pay close attention, in a phenomenological sense, to his inner states of consciousness by detaching himself from his wife and step-daughter Baba. Like Dino, Francesco has feelings of guilt and shame even though he can discover no logical reason for his feelings. They simply exist. He becomes detached and alienated from his wife because he believes the reasons he fell in love with her were and are artificial and nongenuine. Likewise, the diary/novel that is intended to explain his crisis of shame and lack of love shares the same falseness and artificiality. It is not only the book which lacks "genuineness" (13) ["inautenticità," 15], the key concept repeated throughout the "Prologue" and diary, but also reality itself. Upon inspection, not only his own story, but all of history seems false and nongenuine. The major dilemma for Francesco is that something which exists (his marriage, family, love, human ideas and institutions in general) seems to come from nowhere and nothing. This insolvable and seemingly contradictory Heideggerian problem about the provenance of being throws Francesco into despair. His despair is caused by the absence of a way out. If the rational cause and effect relationships are violated, as in the case of existence originating from nothingness, then Francesco concludes there is nothing to be done with any sense to it. His conclusion is that human action is meaningless and inauthentic. Aesthetic action - telling his own story - is simply invention, not reality. Acting in such a way to change human relationships is especially meaningless and inauthentic. Given this state of affairs, he chooses, oddly enough, two ways out of his particular dilemma. He undertakes to write a genuine novel based on everyday life, consciously rejecting the artificial novel based on action. He commits himself to "non-involvement" ["disattenzione"] which he defines as a "feeling of a suspension of involvement ["attenzione," 30], not purely and simply a lack of involvement" (29). Moravia's repetitive and deliberate oppositioning of the terms "attenzione" and "disattenzione" (unfortunately lost in translation) focuses our own attention on Francesco's major problem: what control can the intellectual exercise over his life as he lives it and the feelings he has given the conviction of the inefficacy of all modes of action, whether aesthetic, sexual or ethical? This turns out to be the rhetorical question of the novel which Moravia's narrator invites us to answer.

Since it is a foregone conclusion drawn early in the "Prologue" that all actions, and especially aesthetic actions like writing diary/novels, are inauthentic, unreal and nongenuine, we may wonder why we are expected to wade through the next 300 pages of text which intend to be meaningful but the narrator recognizes early will ultimately be meaningless. We read on because 
we are caught up in Francesco's search for meaning and explanations. We read because of the dramatic interplay of characters and the interrogations they must submit to. We read because Moravia knows how to suck us into the archetypal story of incest and rivalry.

The first diary entry of the body of the novel, "Tuesday October 13th," elaborates Francesco's discovery of his incestuous desire for his step-daughter Baba. After a long interrogation, he becomes fascinated by her as an object that objectifies the nullity Francesco feels in himself and as an object the name for which-incest-incites automatically in him not the impulse for intercourse but the idea of sexual interest. The next diary entries for "Wednesday October 14th" provide Francesco's analysis of his incestuous desires through a reading of Oedipus Rex. The first short entry outlines his own helplessness and inactivity. He argues that Oedipus was able to free himself from the sin of incest through self-punishment and expiation. $\mathrm{He}$, however, cannot act or does not know how to act so as to transform the negativity of sin and guilt into the positive release from or catharsis of error. The oedipal incest motive is related here to Moravia's adaptation of Greek tragedy and the influence of Freud. While there is no evidence that Moravia has pursued structuralist interpretations of Freud, it is tempting to link the aporetic contradictions of Francesco's narrative to Levi-Strauss's analysis of the Oedipus complex as an explanation of the contradiction of human origination laid out in his Structural Anthropology. The Oedipus myth with its traditional insight into familial sexual relationships as well as its revelation of the blindness of mortal knowledge is the kind of equivocal and suggestive story that lends itself perfectly to Moravia's aporetic narratives. The recognition of the contradictions of life and the inadequacy of human logic and language are what Moravia's modern artist/intellectuals must inevitably come to.

In the second entry of "Wednesday October 14th" Francesco discovers that not acting is a choice and ultimately an action. Thus, he concludes that he is not free not to act. Since, no matter what, he is compelled to act simply by making choices, he decides to switch from a non-involved stance to an "attitude of involvement" (69). He calls this attitude "contemplation," which turns out to be both involved and yet not completely so. "Contemplation" is a way to live his life and write his novel. It is a way to live a life both real and unreal, and write a genuine nonactive novel. This is Francesco's aporetic anagnorisis which, as we already know from the "Prologue," will be doomed to failure. This recognition is Moravia's narrative move to insure a dramatic interest in Francesco's search for a way between action and inaction, reality and unreality, authenticity and inauthenticity, and genuineness and nongenuineness. We want to see how Moravia will lead Francesco and us out of his Gidean labyrinth of narrative mirrors. We want to know how it is possible that a committed, non-involved, inattentive narrator such as Francesco will succeed in becoming the uncommitted, yet involved and attentive author of 
a novel about action which he really does not want to commit. But more importantly, Moravia offers "contemplation" not simply as a narrative strategy to revive reader interest; rather, he sees contemplation as a way out. In his essay "Man as an End," he proposes an attitude of contemplation ("contemplazione" is the original term used in both narrative and essay) as an escape from the clutches of the modern world and as a conscientious alternative to the passivity and lack of existential commitment to be found in modern mass cultures. Contemplation is also a rejection of an existentialistic call to action of the type expressed by Camus and Sartre. It is theoretically an independent stance which does not abandon the real world or reality, but also is skeptical of willful actions undertaken in a world where cultural and ideological crises manipulate reactions and obscure them. Man loses his sense of autonomy and freedom when he becomes merely a means for the acting out of the drama of history and not the end, goal or humanistic ideal of historical movements. As Moravia put it in "The modern world will not become a Thebaid," one of the closing sections of his long essay "Man as an End:"

If man wants to rediscover an idea of man and break out of the slavery into which he has fallen, he must be aware of his being a man and, to attain this awareness, he must abandon action for contemplation once and for all. $(59 ; 244)$

The Moravian concept of contemplation in narrative and essay is presented as an aporia or way out of story and history, a way to escape from the nets of human reality. But, of course no one succeeds in escaping.

From this point early in the diary/novel when Francesco undertakes his new attitude of uncommitted involvement or contemplation, we encounter the cross-examinations which, as in The Empty Canvas, attempt to uncover truth. As Francesco concludes at the end of the diary entry "Sunday October 25th," he must follow Oedipus's method and question his wife Cora. We are carried along from diary entry to diary entry in pursuit of the dramatic discovery of why it is that he desires Baba, does not desire Cora, and writes a diary/novel. Writing the novel is, to him, an exercise of freedom, free action and choice, but also a story he is "forced to relate" (106). This contradiction reenforces the recognition which comes at the end of the "Thursday October 29th" entry that he is both imitating reality and inventing it. He confesses that some of his diary entries are lies and prevarications. He conceives that the only way to investigate the truth of things is to identify with them. But he recognizes that this identification is impossible. Francesco wills and desires an identification with Baba and Cora as things and objects; he tries to see them through the "logic of every day normality" (185). But he violates and prevaricates normality in doing so. He sees their tautologous existencesthey are what they are - and he cannot penetrate into this existence without aesthetic invention. The mystery and impenetrability of their automatic and puppet-like lives are impervious to truth. 
As the diary entries progress toward the inevitable "Epilogue" which will end Francesco's desperate speculation, he learns that, in reality, he need do nothing, for death, the "deus ex machina," would take care of everything. Death is the final "corruption" ["corruzione"] of tautologous existence Francesco calls normality and reduces all willful actions to their necessary end:

In conclusion, I should recognize yet again that it was not necessary to act because ordinary everyday life takes care of that for us, and all we have to do is to let it take its course, and when there is nothing else for it to do, it summons forth the deus ex machina of death and everything falls into place. (249-50)

Death is the mechanism that corrupts life and renders it machine-like in its efficiency. History shares this trait. It renders all acts meaningless. History is simply a "senseless sequence of events" (276), an irruption of corruption into the stream of human lives being lived. This pessimism about the meaning of things colors Francesco's conception of his aesthetic enterprise. In an important diary entry, "Friday December 4th," Francesco summarizes his recognition that he is able to write only "nongenuine novels" (275) ["romanzi inautentici," 245] simply because nongenuineness, like the corruption of death and history, is at the heart of all things and all actions, including aesthetic ones.

Francesco recognizes that aesthetic action is doomed to failure, yet he pursues his dream of capturing reality in his diary/novel, for it is his way of loving the world. As he confesses to Baba near the end of his diary:

... the love that I feel for you in real life is merely a mode of action, and there can be no genuineness in action, whereas the love which will allow me to represent you in my novel begins and ends in contemplation and does not become soiled with action, with the dream of action, or with the renunciation of action. (32I)

At this point in the novel, a contemplative love surfaces as the only way out between the nongenuineness of historical and aesthetic action. And it is the only genuine escape from the corruption of death.

True to the aporetic logic inherent in Moravia's narratives, the final diary entry, "Thursday December 17th," offers two conclusions. One Francesco characterizes as a fit ending for a "dramatic novel" ["romanzo drammatico"], while the other will simply make of the diary entries a "drama of a novel" (324) ["il dramma di un romanzo," 288]. Both conclusions are true in their own ways though they cast a different significance or set of meanings over the previous diary entries.

Even as "modern" readers inured to narrative tricks and multiple endings, we are disturbed by the two contradictory conclusions: the one a revelation that the final confession to Baba has been invented, and the other a final confession that really occurred. We face the prospect of having to reread the novel again in at least two quite different ways. Francesco understands our 
hesitations and he appeals to us in the "Epilogue" to be fair to his doubts about the distinctions between appearance and reality. After all, he argues, life is merely a dream. All we can possibly do is either discipline ourselves to dream some dreams and not others (a process he does not understand), or simply rank dreams in order of their apparent relation to reality, making some dreams more real than others. We should at least recognize, he contends, that the dreams were his, genuinely had by him, and thus we should partake of them with some sense of authenticity. At this point, contemplative love as an aporial solution to the countermands of history and art dissolves into oneirocriticism.

Similar to the conclusion of The Empty Canvas, The Lie leaves us in doubt. It is not so much that we do not know how to go on with the investigation of the problem of freedom and nonfreedom; rather it is that we find it difficult to go back to the problem at all because it has been reduced to a doubtful and highly suspect enterprise. Within the metaphor of mechanism which Francesco has applied as an explanation to human destiny as well as to his narrative art, reading The Lie becomes like driving and being driven. Moravia's narrative chauffeur drives us to a certain point (we have gone along for the ride and enjoyment of new prospects), and then we must drive back and recover the route ourselves without a trustworthy map in the company of a confused chauffeur. At any blind intersection, it is our choice which way to go. We have become responsible for the whole narrative territory and landscape. The aporiae of freedom and nonfreedom become our own as we try to choose the best way out of a maze of multiple destinations which results from the contradictory signs in our map/text.

The Empty Canvas and The Lie acutely display the puzzle or aporia of human freedom and nonfreedom. The narrators of the novels appeal to us to investigate with them this dilemma of human life. The investigation is dialectic or aporetic in its logical mode of laying out the contradictions of the problem. There appears to the narrators and to us no resolution to the antinomic interpretations of the narrators' actions. The novels end, as they had begun, with expressions of doubt about the thrust and meaning of their life experiences and aesthetic rendering of those experiences. We are asked, rhetorically or aporetically, to attempt solutions of our own though it becomes quite clear that neither they nor we can possibly proceed in such a confused state of affairs. While the narratives have some relation to Sophoclean tragedy, there are not dramatic resolutions. Like Greek tragedy, however, we find a four-tiered anagnoretic irony in the novels: author, audience, actor and character may display and understand different interpretations of a string of words, a syntax. Thus, in this final sense, the deconstructionist's aporia applies to the multiple and confusing meanings, the "vertiginous possibilities" of interpretations of Moravia's novels of the 1960 s. 


\section{NOTES}

1 For a statement of Moravia's interest in Greek tragedy and a theatre of ideas see Alfonsi (xvxvi). Moravia's use of Wittgenstein in his dramas and 1960s novels is discussed in Siciliano (113-23), Kibler and interviews given at Sabaudia and the Istituto Italiano di Cultura. Ajello's interview reveals Moravia's reading of phenomenology and Husserl (168-9).

21 have used the Manor Books edition of The Empty Canvas which has the same pagination and translator as the Farrar, Straus and Cudahy edition (1961). I provide the Italian original when there is special terminology or when the original differs from its English translation. I have used the Tascabili Bompiani edition of La noia.

3 Page numbers are from the Manor Books edition which has the same pagination and translator as the Farrar and Straus edition of The Lie (1966). Where necessary, I have supplied the Italian original from the Bompiani edition of L'attenzione.

\section{WORKS CITED}

Ajello, Nello. Alberto Moravia. Bari: Laterza, 1978.

Alfonsi, Ferdinando and Sandra Alfonsi. An Annotated Bibliography of Moravia Criticism in Italy and the English Speaking World (1929-1975). New York: Garland, 1976.

de Man, Paul. Allegories of Reading: Figural Language in Rousseau, Nietzsche, Rilke and Proust. New Haven: Yale UP, 1979.

Blindness and Insight: Essays in the Rhetoric of Contemporary Criticism. Second ed. rev. Minneapolis: U of Minnesota P, 1983.

Hartmann, Nicolai. Ethics. Trans. Stanton Coit. 3 vols. London: Allen and Unwin, 1932.

Istituto Italiano di Cultura. Recorded interview with Moravia. New York, May 19-20, 1968. Unpublished.

Kibler, Louis. "Moravia's Empty Canıas: A Literary Application of Wittgenstein." Unpublished paper.

Recorded interview with Moravia. Sabaudia, June 4, 1973. Unpublished.

Levi-Strauss, Claude. Structural Anthropology. New York: Basic Books, 1963.

Moravia, Alberto. L'attenzione. Milano: Bompiani, 1980.

The Lie. Trans. Angus Davidson. New York: Manor Books, 1973.

Man as an End: A Defense of Humanism. Trans. B. Wall. New York: Farrar, Straus and Giroux, 1965.

La noia. Milano: Bompiani, 1981.

L'uomo come fine e altri saggi. Milano: Bompiani, 1964.

Siciliano, Enzo. Moravia. Milano: Longanesi, 1971.

Wittgenstein, Ludwig. Tractatus Logico-Philosophicus. Trans. D.F. Pears and B.F. McGuinness.

London: Routledge \& Kegan Paul, 1961. 